\title{
Removal of PCDD/Fs and CBzs by different Air Pollution Control Devices in MSWIs
}

\author{
Tong Chen ${ }^{1 *}$, Chen Sun ${ }^{1}$, Tianjiao Wang ${ }^{2}$, Mingxiu Zhan ${ }^{3,1}$, Xiaodong Li ${ }^{1}$, Shengyong Lu ${ }^{1}$, \\ Jianhua Yan ${ }^{1}$ \\ ${ }^{1}$ State Key Laboratory of Clean Energy Utilization, Institute for Thermal Power Engineering, Zhejiang University, \\ Hangzhou 310027, China \\ ${ }^{2}$ Institute of Incineration Technology, Everbright Envirotech (China) Ltd., Nanjing 211102, China \\ ${ }^{3}$ College of Metrology and Measurement Engineering, China Jiliang University, Hangzhou 310018, China
}

\begin{abstract}
This study investigated the removal efficiencies of polychlorinated dibenzo-p-dioxins and polychlorinated dibenzofurans (PCDD/Fs) and chlorobenzenes (CBzs) by different air pollution control devices (APCDs) in three municipal solid waste incinerators (MSWIs). These devices were the semi-dry flue gas desulfurization (SDFGD) system, activated carbon (AC) injector, bag filters (BF), selective catalytic reduction (SCR) reactor, and wet scrubber. The SDFGD system, AC injector, and $\mathrm{BF}$ exhibited similar removal efficiencies for all of the pollutants. Overall, the removal efficiency of CBzs was also considerably lower than the PCDD/Fs. The less chlorinated CBzs were also less likely to be adsorbed by AC and BF and more likely to be decomposed by the SCR reactor. Additionally, the "memory effect" in the wet scrubbers elevated the concentrations of the PCDD/Fs and even the CBzs in the flue gas, with the highest increases observed for penta- to heptachlorinated PCDD/Fs and TrCBzs. Given the different effects of these various devices, especially the wet scrubber, the correlation between PCDD/F and $\mathrm{CBz}$ removal should be individually assessed for each APCD unit. More accurate indicators of PCDD/F removal are also examined.
\end{abstract}

Keywords: Polychlorinated dibenzo-p-dioxins and polychlorinated dibenzofurans; Chlorobenzenes; Air pollution control devices; Correlations; Emission characteristics.

\section{INTRODUCTION}

Typical organic pollutants, such as polychlorinated dibenzo-p-dioxins and polychlorinated dibenzofurans (PCDD/Fs), chlorobenzenes (CBzs) and chlorophenols, can be found throughout the whole process of municipal solid waste incinerator (MSWI) with various concentration levels. Researchers have found that there are various persistent organic pollutants in the bottom ash, fly ash and the flue gases before and after the air pollution control devices (APCDs) (Dong et al., 2002; Takaoka, 2002; Oh et al., 2007; Yan et al., 2010; Hu et al., 2013; Han et al., 2017; Hsieh et al., 2018). The characteristics and relationships of PCDD/Fs and chlorobenzenes as indicators have also been studied (Ballschmiter et al., 1988; Altwicker et al., 1992; Kato and Urano, 2001; Lavric et al., 2005; Yin et al., 2007; Gullett et al., 2011). In our previous research, the emission

\footnotetext{
* Corresponding author.

E-mail address: chentong@zju.edu.cn
}

characteristics of PCDD/Fs and CBzs in flue gas before the APCDs and in the stack have been investigated along with their correlation models (Wang et al., 2017a, b; Chen et al., 2018). However, the removal efficiencies of PCDD/Fs and CBzs by the semi-dry flue gas desulfurization (SDFGD) system, activated carbon (AC) injection, bag filters (BF), the selective catalytic reduction (SCR) reactor, and the wet scrubber have not been comprehensively studied. Furthermore, influences on the correlation models of PCDD/Fs and CBzs by each APCDs unit have not been investigated.

APCDs play vital roles in controlling pollutant emissions from MSWIs and can substantially affect the characteristics of both PCDD/Fs and CBzs. The common related technologies most commonly used in the MSWIs include SDFGD, wet scrubbers, selective non-catalytic reduction (SNCR), SCR, $\mathrm{AC}$ adsorption, $\mathrm{BF}$, and electrostatic precipitators (ESPs) (Kulkarni et al., 2008; Wielgosiński, 2010; Li et al., 2017; Zhou, 2017)

SDFGD and wet flue gas desulfurization are methods commonly employed to control acid gas pollutants, such as $\mathrm{HCl}, \mathrm{SO}_{2}$ and $\mathrm{NO}_{x}$. The use of calcium oxide or calcium hydroxide powders can also affect the characteristics of 
PCDD/Fs and CBzs. The wet scrubber is also a typical deacidification device. Wevers et al. (1992) found that $71 \%$ of PCDD/Fs in the flue gas could be removed by the wet scrubber. However, because of the existence of "memory effects," which typically burden clean flue gas but clean dirty flue gas, increasing concentrations of PCDD/Fs could also be found (Trivedi and Majumdar, 2013). SNCR and $\mathrm{SCR}$ technologies are widely used in $\mathrm{NO}_{x}$ reduction. Aminoreductants employed in SNCR systems also suppress the formation of PCDD/Fs (Ruegg and Sigg, 1992; Ruokojärvi et al., 1998, 2001; Kuzuhara et al., 2005). Additionally, novel catalysts used in SCR systems nowadays facilitate the joint degradation of $\mathrm{NO}_{x}$ and PCDD/Fs (Kulkarni et al., 2008; Wielgosiński, 2010).

ESPs and BF are employed to remove particulate matter from flue gas. ESP is suitable for use in a range of adverse circumstances at high temperature. However, it is sensitive to particle size and fails to remove gaseous pollutants. ESP is also one of the main sources for the formation of PCDD/Fs. Bag filters are suitable for various flue gases and have high removal efficiencies; however, they are easily damaged because of filter materials. Bag filters are able to remove solid phase PCDD/Fs attached to particles. However, memory effects on PCDD/Fs were found (Trivedi and Majumdar, 2013). AC is used to remove heavy metals, ultrafine particles, $\mathrm{PCDD} / \mathrm{Fs}$ and other organic pollutants (Wielgosiński, 2010). Bag filters and AC injection are a conventional unit of APCDs in numerous MSWIs.

APCDs might also have a significant influence on the relationship between $\mathrm{PCDD} / \mathrm{Fs}$ and CBzs. CBzs as significant precursors and indicators, have an adequate relationship with PCDD/Fs, and can be used to indirectly monitor and control their emissions (Lavric et al., 2005; Gullett et al., 2011). However, the influences of each APCD unit on the relationship of between PCDD/Fs and CBzs remain unknown. In this research, the concentrations, fingerprint characteristics of, and relationships between PCDD/Fs and CBzs before and after the applications of different air purification units of three MSWIs were studied.

\section{METHODS}

\section{Sample Collection}

The samples were collected from three grate furnaces in one municipal solid waste incineration plant in eastern China. Each furnace had a capacity of $750 \mathrm{t} \mathrm{d}^{-1}$. The APCD system included SNCR, SDFGD, AC injection, BF, steam gas heater ( $\mathrm{SGH}), \mathrm{SCR}$, wet scrubber, and gas-gas heater $(\mathrm{GGH})$. Basic information on each of these is presented in Table 1, and a schematic diagram of APCD system is shown in Fig. 1.

The original flue gas from the boiler first entered the SDFGD to remove acid gases. Heavy metals, PM, and $\mathrm{PCDD} / \mathrm{Fs}$ were then removed through the bag filter with an $\mathrm{AC}$ injection. Following the steam gas heater, flue gas entered the SCR reactor. The SCR reactor was put after BF to avoid the destructive effect of PM on the SCR catalyst. Both PCDD/Fs and $\mathrm{NO}_{x}$ were removed using special catalysts. The acid gas was then removed once again in the wet scrubber at the end to achieve the ultra-low emission standard. After several removals of $\mathrm{SO}_{2}, \mathrm{NO}_{x}, \mathrm{PM}$ and $\mathrm{PCDD} / \mathrm{Fs}$, the emitted flue gas was generally clean.

Flue gas samples were collected simultaneously in the APCD systems of each MSWI. The sample sites were the

Table 1. The basic information of MSWIs investigated.

\begin{tabular}{ll}
\hline & MSWI I, II, and III \\
\hline Type of furnace & Stock \\
Capacity $\left(\mathrm{t} \mathrm{d}^{-1}\right)$ & 750 \\
Combustion temperature designed $\left({ }^{\circ} \mathrm{C}\right)$ & 950 \\
Operation duration $(\mathrm{m})$ & 10 \\
APCD system & SNCR + SDFGD + AC injection + BF + SGH + SCR + wet scrubber \\
& + GGH \\
\hline
\end{tabular}

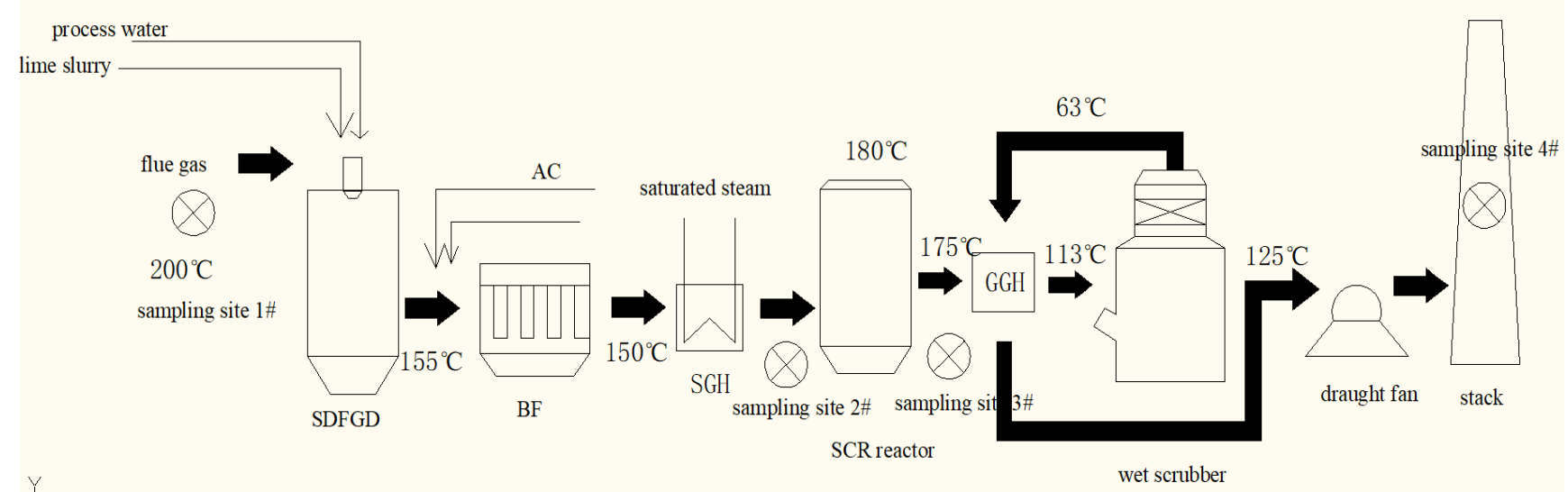

Fig. 1. The technological process of flue gas purification system. 
SDFGD inlet (named \#1), the SCR reactor inlet (\#2), the SCR reactor outlet (\#3), and the stack (\#4), as shown in Fig. 1. The temperature and oxygen content in each of the sampling conditions are listed in Table 2.

All flue gas samples were collected in accordance with U.S. EPA Method 23 (EPA, 1995) by using an isokinetic sampler (KNJ, Korea). Each sample was collected for approximately $2.0 \mathrm{~m}^{3}$. The part in the particulate phase was collected in the filter, whereas the part of the sample in the gaseous phase was collected in XAD-II resin.

The extraction method employed in previous research was used for all the samples collected (Oh et al., 2007). The samples were extracted stepwise with methylene chloride and toluene and then concentrated separately. This step was undertaken to prevent the losses of semi-volatile compounds such as chlorobenzenes. The aliquots of the concentrated samples were used for the cleanup and analysis of PCDD/Fs and $\mathrm{CBz}$. The $\mathrm{PCDD} / \mathrm{F}$ cleanup procedure and analysis were conducted in accordance with the standard of U.S. EPA Method 23a (EPA, 1995). A 6890 Series gas chromatograph (Agilent, USA) coupled with a JMS-800D mass spectrometer (JEOL, Japan), comprised the high-resolution gas chromatograph/high-resolution mass spectrometer (HRGC/HRMS) used for the identification and quantification of PCDD/Fs. The capillary column used was DB-5ms (60 m $\times 0.25 \mathrm{~mm}$ I.D., $0.25 \mu \mathrm{m}$ film thickness). Details of the temperature programming used for the column can be found in previous research (Wang et al., 2017a, b).

The recovery of PCDD/Fs in all samples was within the range required. Based on standards for pollution control at municipal solid waste incinerators in China, the international toxic equivalency factors (I-TEFs) (Bhavsar et al., 2008) were employed to calculate the toxic equivalency values (TEQs) of PCDD/Fs. All concentrations were normalized to dry air, $11 \%$ of oxygen content, $101 \mathrm{kPa}$, and $237 \mathrm{~K}$.

The pretreatment and detection of CBzs were previously described thoroughly by Yan et al. (2012). GC-ECD (GC $6890 \mathrm{~N}$; Agilent, USA) involved with a DB-5 column $(30 \mathrm{~m} \times$ $0.25 \mathrm{~mm} \times 0.25 \mu \mathrm{m}$ ) was adopted to measure the concentration.

\section{RESULTS AND DISCUSSION}

\section{Effects on the Total Concentrations of PCDDs, PCDFs and $\mathrm{CBz}$ s}

The concentration of PCDD/Fs in the flue gas passing through the APCDs in three MSWIs are presented in Fig. 2. The concentrations of PCDD/Fs in the original flue gas of three MSWIs were $1.1,2.2$, and $1.0 \mathrm{ng} \mathrm{I-TEQ} \mathrm{Nm}^{-3}$, respectively. The original pollutant values emitted were rather low in most Chinese MSWIs. This is primarily due to the new technology designed for the grate. Each column moves as one unit, and shear knives are set in the combustion

Table 2. The main information of experimental conditions.

\begin{tabular}{|c|c|c|c|c|c|}
\hline \multicolumn{6}{|c|}{ Experimental conditions } \\
\hline \multirow[t]{4}{*}{ Furnace temperature $\left({ }^{\circ} \mathrm{C}\right)$} & MSWI I & 948 & & & \\
\hline & MSWI II & 908 & & & \\
\hline & MSWI III & 964 & & & \\
\hline & & $\# 1$ & $\# 2$ & $\# 3$ & $\# 4$ \\
\hline \multirow[t]{3}{*}{ Temperature at the sampling site $\left({ }^{\circ} \mathrm{C}\right)$} & MSWI I & 200 & 180 & 175 & 201 \\
\hline & MSWI II & 204 & 181 & 172 & 200 \\
\hline & MSWI III & 198 & 179 & 174 & 201 \\
\hline \multirow[t]{3}{*}{ Oxygen content at the sampling site $(\%)$} & MSWI I & 8.8 & 9.2 & 9.2 & 9.3 \\
\hline & MSWI II & 9.1 & 9.2 & 9.2 & 9.6 \\
\hline & MSWI III & 7.5 & 8.3 & 8.3 & 8.6 \\
\hline
\end{tabular}

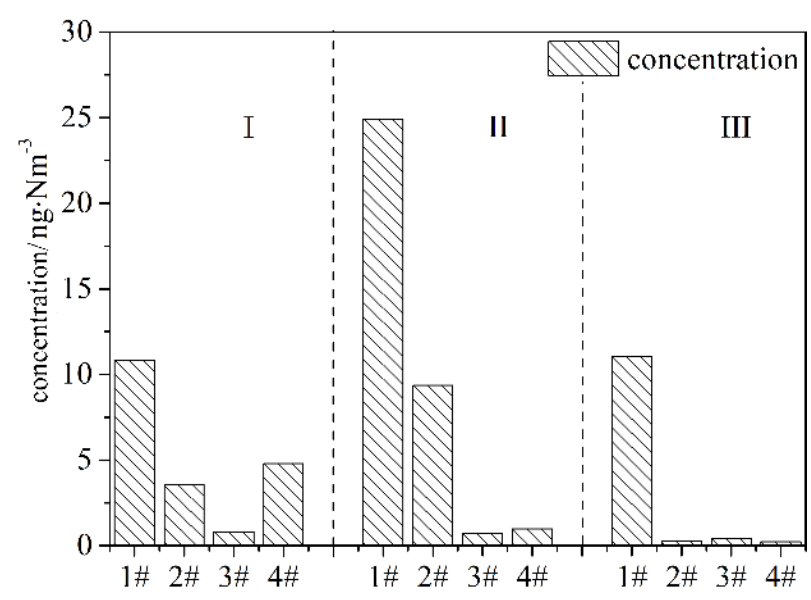

(a)

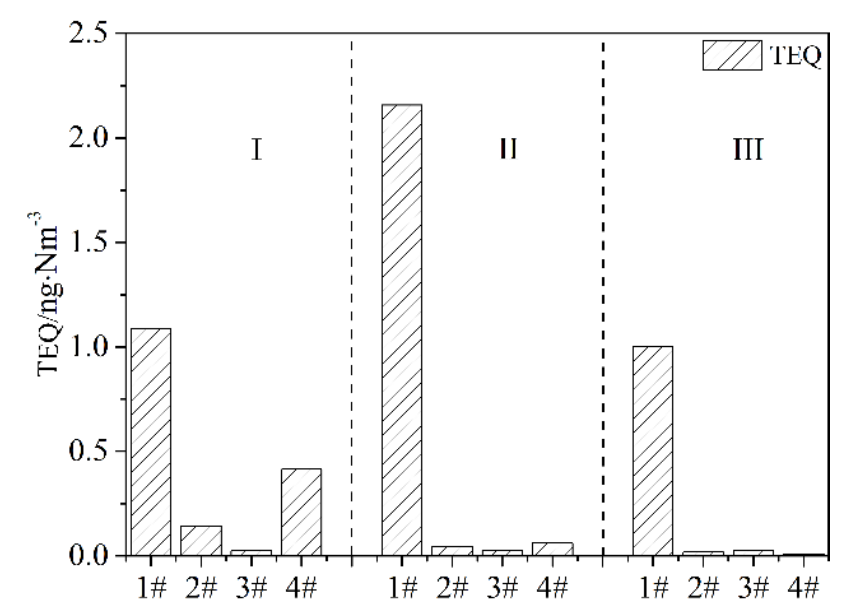

(b)

Fig. 2. PCDD/F concentrations and TEQ in the flue gas from MSWIs. 
section to break up caked waste and improve combustion conditions. Excellent operation in time during the combustion also exhibited good effects. Low levels of pollution produced from the furnace assisted the subsequent purification steps.

After applying the SDFGD cleaning system with AC and $\mathrm{BF}$, the concentrations of $\mathrm{PCDD} / \mathrm{Fs}$ decreased to $0.14 \mathrm{ng}$ I-TEQ $\mathrm{Nm}^{-3}$. The SCR reactor then reduced the TEQ value even further to only $0.026 \mathrm{ng}$ I-TEQ $\mathrm{Nm}^{-3}$, which is rather lower than the national standard of $0.1 \mathrm{ng} \mathrm{I}^{-T E Q ~} \mathrm{Nm}^{-3}$. However, the wet scrubber at the end increased the concentration of PCDD/Fs to $0.4 \mathrm{ng} \mathrm{I}^{\mathrm{T}} \mathrm{TEQ} \mathrm{Nm}^{-3}$, resulting in excess emissions. Similar results were also found in MSWI II. For instance, the TEQ value decreased from 2.16 to $0.043 \mathrm{ng}$ I-TEQ $\mathrm{Nm}^{-3}$ using the SDFGD with AC and BF and then fell even further to $0.028 \mathrm{ng}$ I-TEQ $\mathrm{Nm}^{-3}$ through the SCR reactor, but the TEQ value then increased to 0.061 ng I-TEQ Nm${ }^{-3}$ because of the effects of the wet scrubber. The results showed that the SDFGD with $\mathrm{AC}$ and $\mathrm{BF}$ worked effectively in all MSWIs with removal efficiencies of $87.0 \%, 98.0 \%$, and $98.2 \%$, respectively. This purification system is widely used in nearly all MSWIs. This shows that an effectively functioning system could achieve high removal efficiencies of PCDD/Fs, especially in newly built MSWIs. However, the SCR reactor and wet scrubber had different effects on the concentration of PCDD/Fs. SCR is a technology typically used to remove $\mathrm{NO}_{x}$ coupled with PCDD/Fs to reach near-zero emissions of PCDD/Fs. Among the three MSWIs investigated, the SCR reactor exhibited a high PCDD/F removal efficiency of $81.8 \%$ and a low efficiency of $33.5 \%$ in two MSWIs. However, in MSWI III, it did not work effectively. The removal efficiency of catalysts in flue gas is largely affected by several complex factors, such as temperature, flue gas velocity, moisture, and oxygen content (Tian et al., 2010). The rather lower concentrations before SCR in MSWI II and III, which fell to as low as 0.05 and even $0.01 \mathrm{ng}$ I-TEQ $\mathrm{Nm}^{-3}$, respectively, also resulted in weaker removal efficiencies, compared with the experimental results of other studies (Yu et al., 2016a, b). Similarly, the wet scrubber also had different effects on the removal of PCDD/Fs. In MSWI I and II, the wet scrubber promoted the formation of PCDD/Fs, whereas the concentrations of PCDD/Fs in flue gas from MSWI III decreased when flue gas passed through the wet scrubber. The removal effect can be attributed to alkaline compounds used in the wet scrubber. However, this effect on PCDD/Fs is limited because the memory effect, which mainly results in high concentrations of PCDD/Fs, is common in the wet scrubber (Trivedi and Majumdar, 2013). The memory effect is thus a really significant factor in controlling PCDD/Fs.

A similar variation was also found in the total concentrations of CBzs when flue gas passed through APCDs. As shown in Fig. 3, the average concentration of CBzs in original flue gas from the furnace was $3.25 \mu \mathrm{g} \mathrm{Nm}^{-3}$, nearly 1,000 times higher than that of PCDD/Fs. This was similar to results for fluid bed incinerators (Wang et al., 2017a, b). The SDFGD system with $\mathrm{AC}$ and BF had the same effect on CBzs in all three MSWIs. The removal efficiencies were 48.4\%, 51.6\%, and $67.5 \%$ for MSWI I, II, and III, respectively. The SCR reactors in MSWI I and II also showed adequate removal

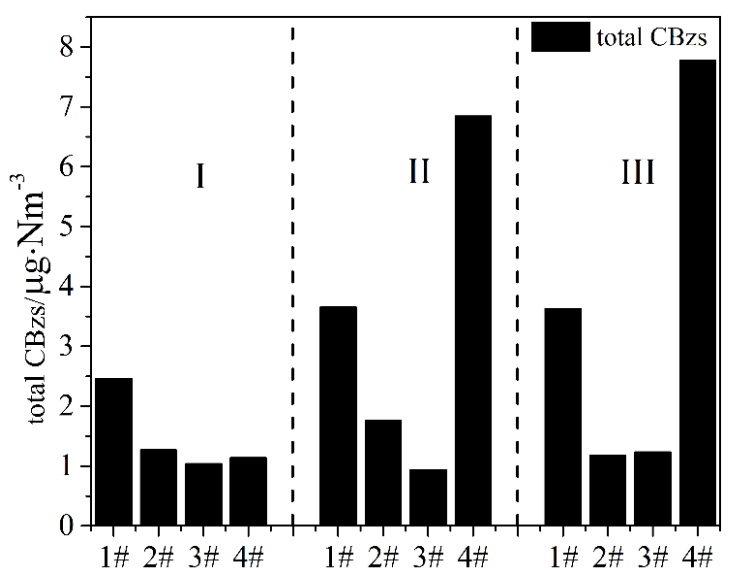

Fig. 3. The total concentrations of CBzs in the flue gas.

effects on CBzs, which was consistent with the effects on PCDD/Fs. The concentrations of CBzs in flue gas decreased from 1.27 to $1.04 \mu \mathrm{g} \mathrm{Nm} \mathrm{Nm}^{-3}$ for MSWI I and 1.77 to $0.94 \mu \mathrm{g} \mathrm{Nm}^{-3}$ for MSWI II, respectively. However, the removal efficiencies were different from those of PCDD/Fs. In MSWI I, the removal efficiency of PCDD/Fs was higher than that of CBzs, whereas the opposite was the case in MSWI II. Furthermore, the concentrations of CBzs were significantly affected by the wet scrubbers. The total concentration of CBzs increased in all MSWIs when flue gas passed through the wet scrubber, especially in MSWI II and III, where the concentrations increased by 6.3 and 5.2 times, respectively. This shows that the effects of wet scrubbers on PCDD/Fs and CBzs are considerably more complicated.

\section{Effects on the Total Concentrations of PCDD/Fs and Gas-solid Phase Distribution}

This research also assessed the gas-solid phase distributions of PCDD/Fs in flue gas through all APCDs from three MSWIs. As shown in Fig. 4, gaseous PCDD/Fs accounted for $90 \%$ of the total concentration of original flue gas at SDFGD inlets in three MSWIs, and the corresponding TEQ value reached 97\%. In MSWI I, the gas-solid distribution of PCDD/Fs changed considerably through the SDFGD system with AC and BF. More highly chlorinated PCDD/Fs with low toxic equivalency factors were present in the particulate matter, and the AC could not adsorb and remove them easily. Thus, the proportion of gaseous PCDD/Fs fell to $66.3 \%$. A similar trend was also evident in MSWI III, where the proportion of gaseous PCDD/Fs decreased from $98 \%$ to $90 \%$. Taking the gas-solid distribution of PCDD/Fs through the SCR reactors and wet scrubbers into account, gaseous PCDD/Fs dominated in all flue gas from furnaces and the SDFGD system with AC and BF had the strongest effect on the gas-solid phase distribution of PCDD/Fs.

The investigation of PCDDs and PCDFs in flue gas from three MSWIs is shown in Fig. 5. The ratios of PCDD and PCDF in original flue gas and final emissions from the three MSWIs were all lower than 1.0. In MSWI I, the concentrations of both PCDDs and PCDFs decreased and then increased when flue gas passed through the APCD system. Following the SDFGD system with AC and BF, the 


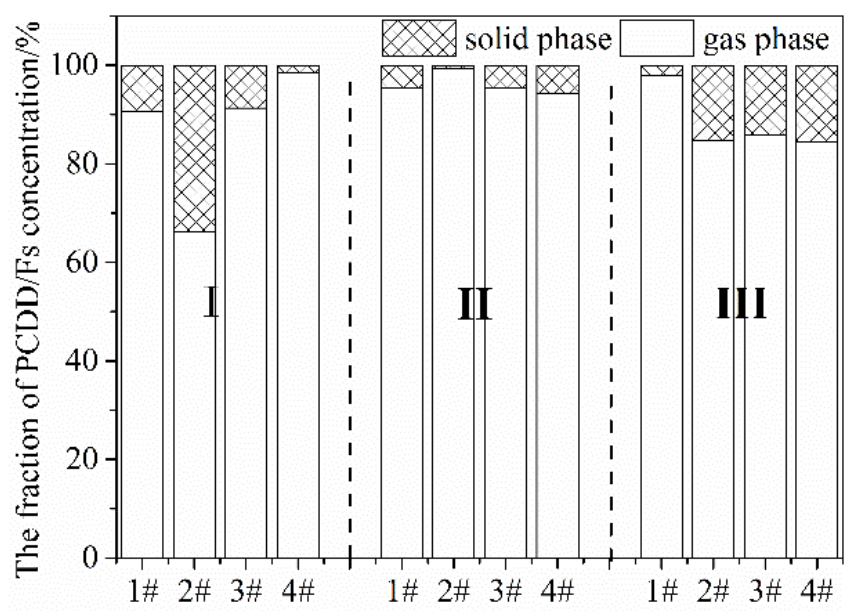

(a)

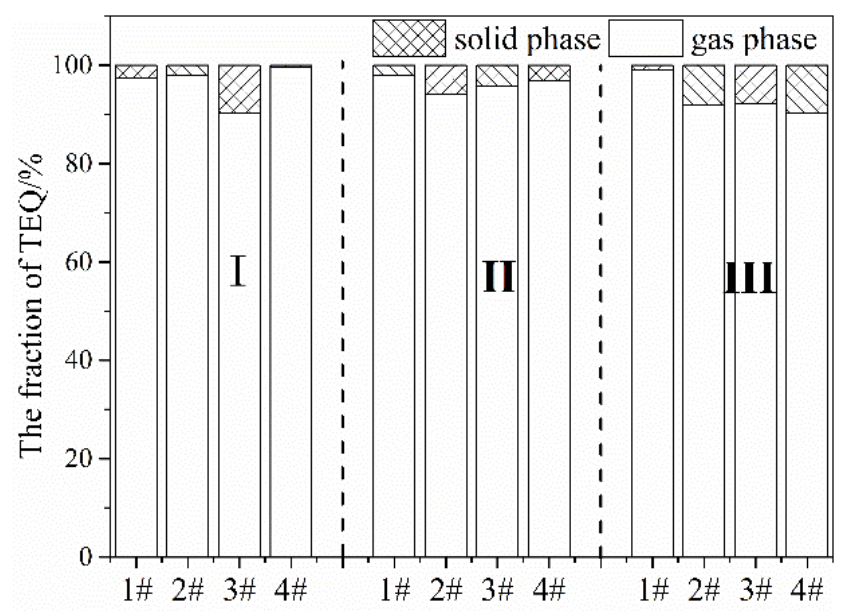

(b)

Fig. 4. The gas-solid distribution of PCDD/Fs in the flue gas through the APCDs.

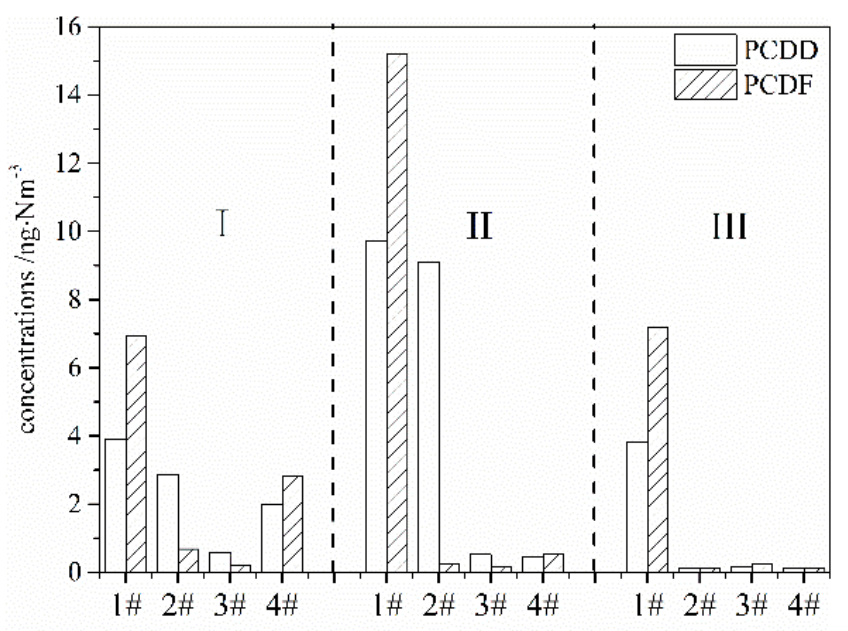

(a)

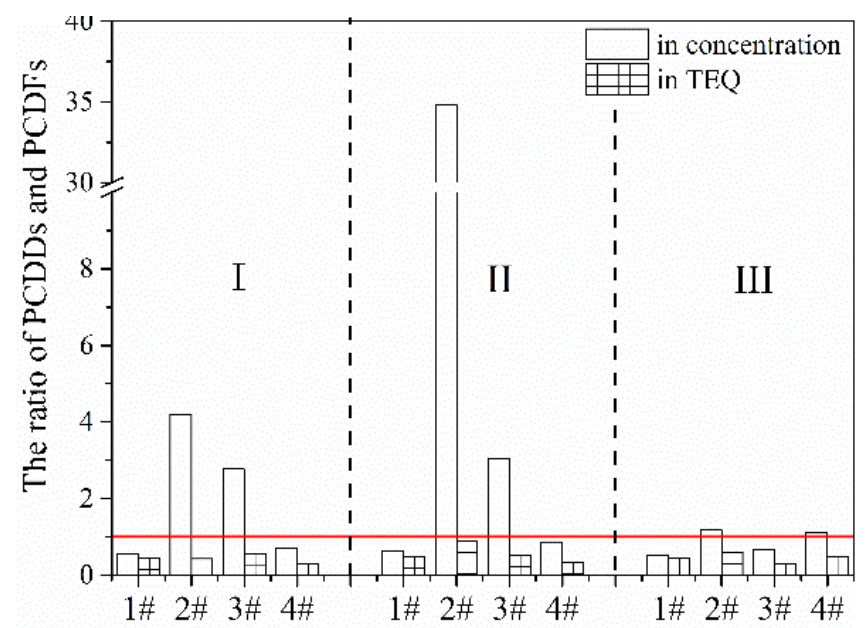

(b)

Fig. 5. The concentration of PCDDs and PCDFs in the flue gas.

ratio of PCDDs to PCDFs increased to 4.0, including that PCDFs are easier to be remove than PCDDs. However, the ratio of PCDDs and PCDFs decreased to 2.7 in the SCR reactor because of a more adequate removal effect was found on PCDDs than on PCDFs. Both PCDDs and PCDFs increased through the wet scrubber of MSWI I, especially PCDF. In MSWI II, the SDFGD system with AC and BF, the SCR reactor, and the wet scrubber had similar effects on PCDDs and PCDFs. In MSWI III, both PCDDs and PCDFs decreased, especially PCDFs, which differed from the result obtained from MSWI I.

Different APCDs had different effects on PCDDs and PCDFs. More PCDFs could be removed by the SDFGD system with $\mathrm{AC}$ and $\mathrm{BF}$, whereas more PCDDs could be removed by the SCR reactor. The wet scrubber also had a relatively strong impact on PCDFs.

\section{Effects on CBz, Homologues}

The concentration fractions of different chlorobenzenes in flue gas at the four sample sites of three MSWIs were also studied. As shown in Fig. 6, the homologue distributions of $\mathrm{CBz}$ were the same in all the APCD systems of three MSWIs investigated. These decreased as chlorination increased. Notably, trichlorobenzenes (TrCBzs) contributed most to the total concentration of CBz. For MSWI I, the concentration fractions of tri- to hexa-chlorobenzenes were $48.1 \%, 28.9 \%$, $18.5 \%$, and $4.5 \%$, respectively. TrCBzs dominated in all flue gas samples, especially flue gas between the SDFGD and BF with the addition of $\mathrm{AC}$. The concentrations of 1,3,5-TrCBz, 1,2,4-TrCBz, and 1,2,3-TrCBz are compared in Fig. 7. This shows that $1,3,5-\mathrm{TrCBz}$ had the lowest concentration in the flue gas of the entire APCD system. The distribution of 1,2,3-TrCBz and 1,2,4-TrCBz varied considerably in different conditions. For instance, we found that the concentration of 1,2,4-TrCBz was higher than that of 1,2,3-TrCBz before the purification of flue gas. However, a different pattern was observed after the purification of flue gas, where the concentration of $1,2,4-\mathrm{TrCBzs}$ in flue gas at Sample Position \#1 from MSWI II reached $0.78 \mu \mathrm{g} \mathrm{Nm}^{-3}$. The fractions of 1,2,4-TrCBz generally decreased when flue gas 


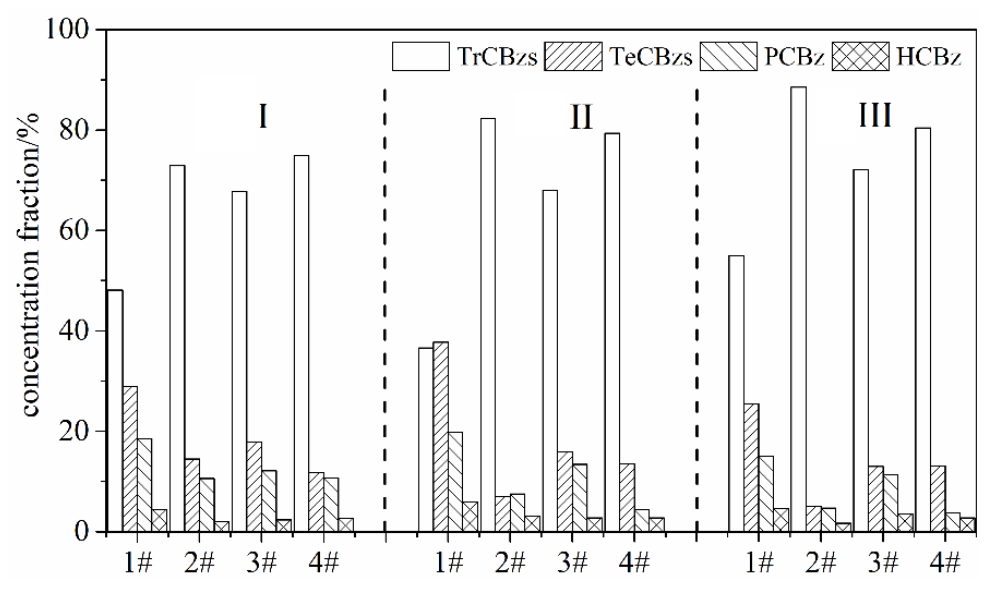

Fig. 6. The concentration fractions of CBzs in the flue gas at different positions.

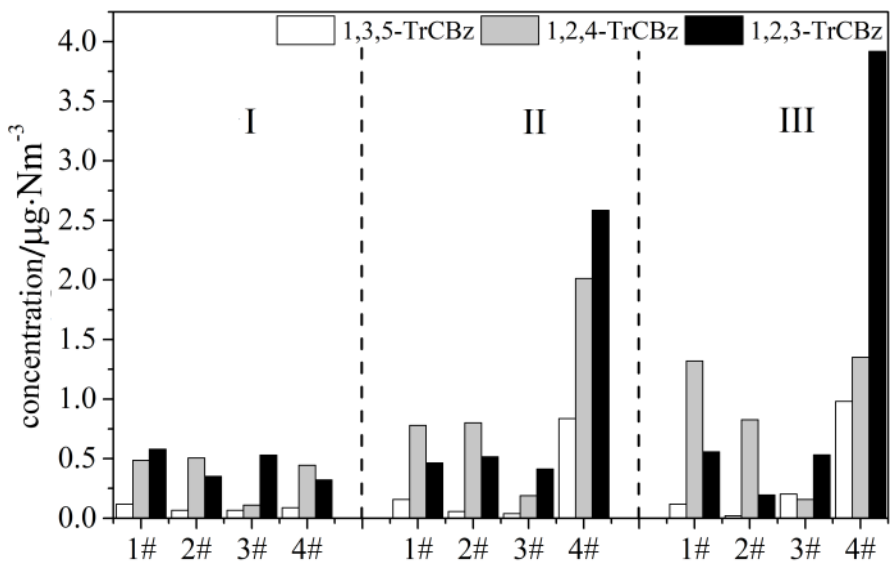

Fig. 7. The concentrations of $\mathrm{TrCBz}$ isomers in the flue gas at different positions.

passed through the SCR system. Furthermore, 1,2,3-TrCBz contributed most to the TrCBzs with fractions of $47.5 \%$ and $62.7 \%$ in flue gas after the wet scrubbers of MSWI II and III, respectively.

\section{Removal Efficiencies of PCDD/Fs and CBzs by the SDFGD System with $A C$ and $B F$}

The concentration distributions of 17 toxic PCDD/Fs before and after the SDFGD system with AC and BF in three MSWIs were presented in Fig. 8. Before purification, gaseous PCDD/Fs in flue gas from MSWI I primarily consisted of 1,2,3,4,6,7,8-HpCDD， OCDD， 1,2,3,7,8-PeCDF and $1,2,3,4,6,7,8-\mathrm{HpCDF}$ with fractions of $10.1 \%, 13.4 \%, 10.8 \%$, and $11.7 \%$, respectively. Fewer differences were found in the distributions of PCDFs. In the solid phase, OCDD contributed a rather high percentage of $50.6 \%$ to the total concentrations. 1,2,3,4,6,7,8-HpCDD, 1,2,3,4,6,7,8-HpCDF and OCDF were also the main congeners with fractions of $12.9 \%, 10.2 \%$ and $8 \%$, respectively. After purification, the concentration of less chlorinated gaseous PCDD/Fs decreased; thus, OCDD contributed most to the total concentration with a fraction of $66.2 \%$. Regarding the solid phase PCDD/Fs, most decreased simultaneously except for OCDD. The distributions of PCDD/Fs in flue gas from MSWI II and III were similar to those in MSWI I.
The removal efficiencies of PCDD/Fs in all three MSWIs were rather similar. For example, the removal efficiencies of each PCDD/F congener in flue gas from MSWI III were greater than 70\%, as shown in Fig. 9. All gaseous PCDD/Fs were significantly removed, with the efficiencies higher than $90 \%$.

The removal efficiencies of CBzs are shown in Fig. 10. Compared with other CBzs, TrCBzs were difficult to remove with APCDs. For instance, in flue gas from MSWI I and II, the removal efficiencies of teta- to hexa-chlorobenzenes were above $60 \%$, whereas the removal efficiencies of TrCBzs were only $21.8 \%$ and $8.7 \%$, respectively. The removal efficiency of TrCBzs in flue gas from MSWI III was $47.8 \%$, whereas the efficiencies of other CBzs reached almost nearly $90 \%$. This could be due to the selection adsorption capacity of CBzs by AC. Normally, highly chlorinated CBzs have considerably higher boiling points and lower saturated vapor pressure and thus can be much more easily removed. Furthermore, the removal efficiency of all CBzs was affected by the low removal capacity of TrCBzs and the relatively high ratio of TrCBzs to the total number of CBzs. In fact, the activated carbon was chosen based on the adsorption performance of PCDD/Fs not the CBzs, thus the removal efficiency of CBzs might be lower than that of $\mathrm{PCDD} / \mathrm{Fs}$. 

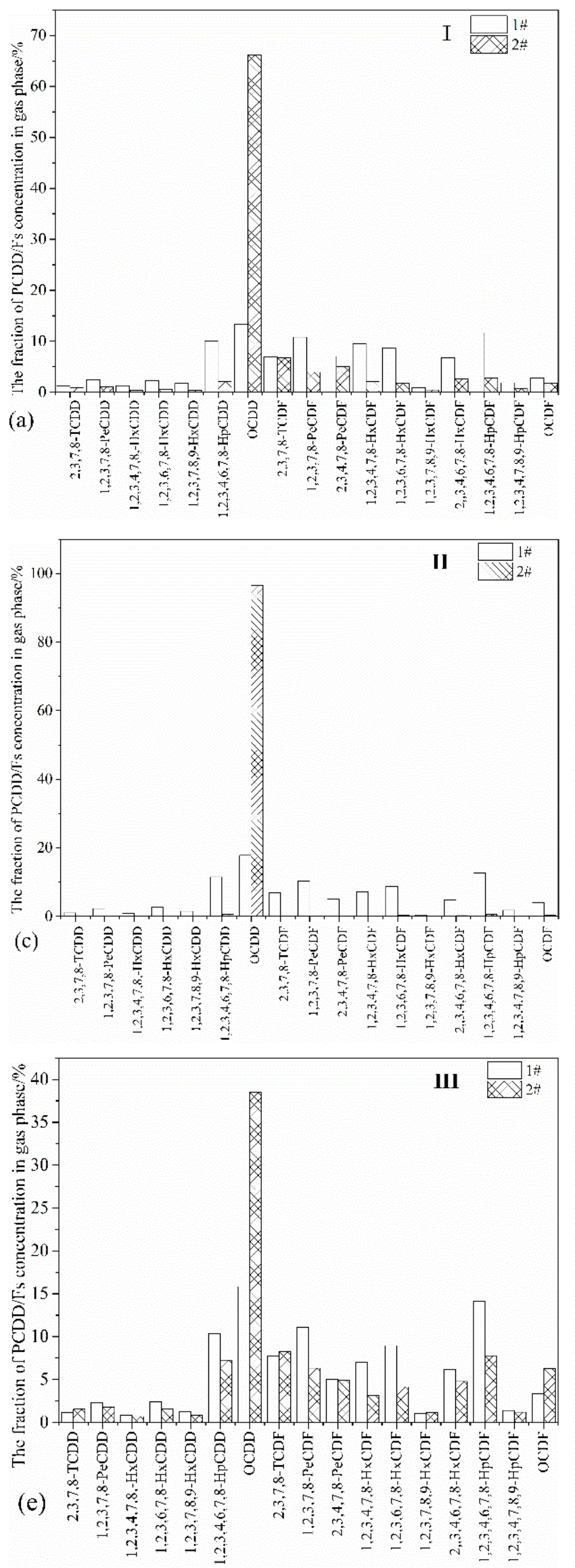
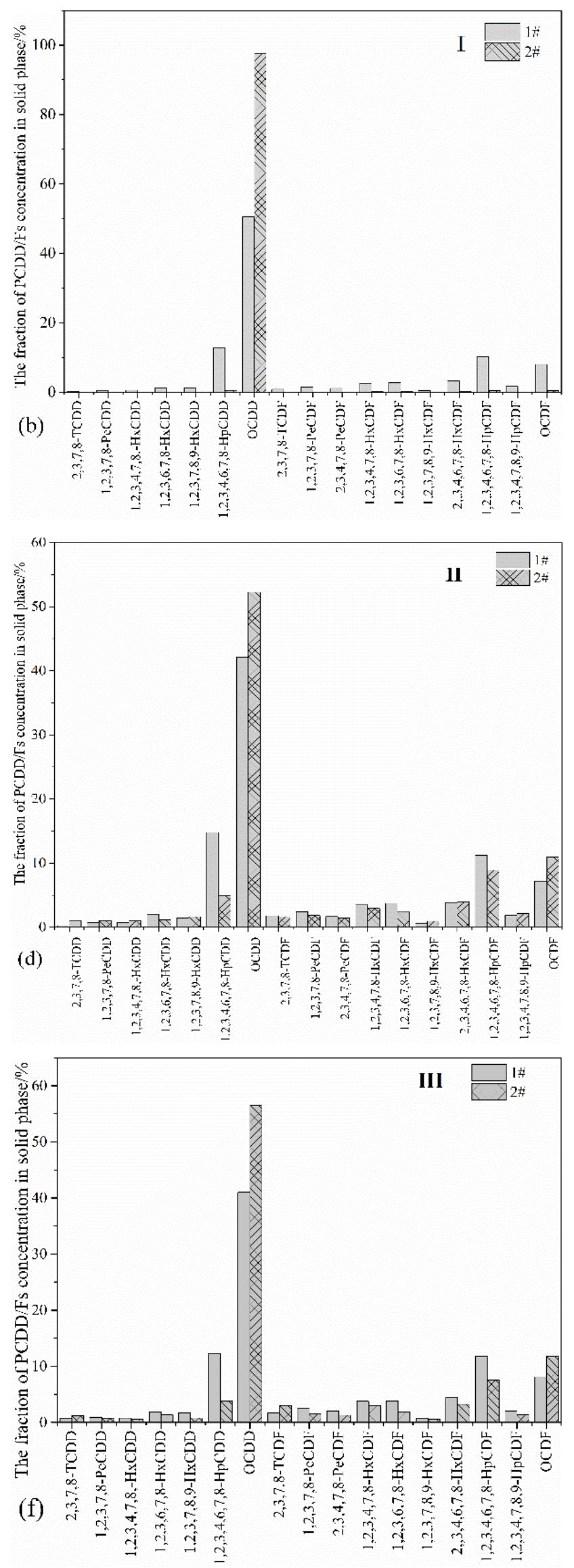

Fig. 8. The distributions of 17 toxic PCDD/Fs through SDFGD system. 


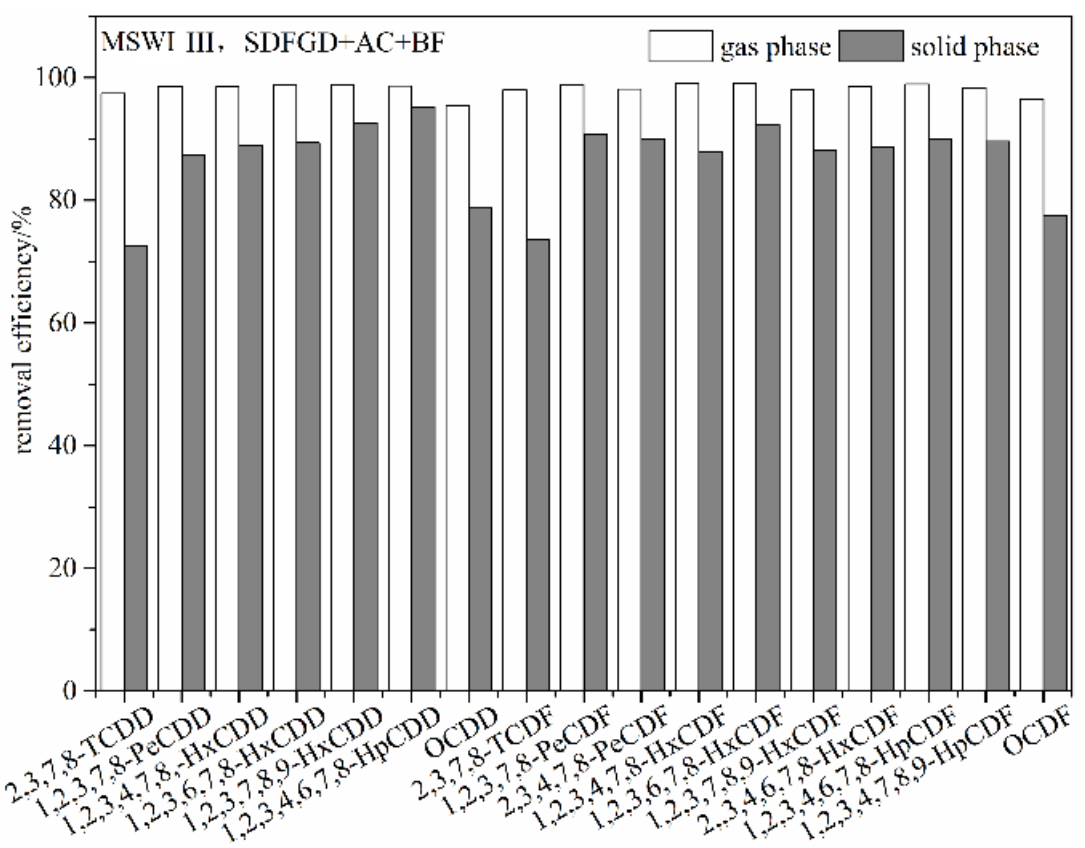

Fig. 9. The removal efficiencies of 17 toxic PCDD/Fs from SDFGD $+\mathrm{AC}+\mathrm{BF}$.

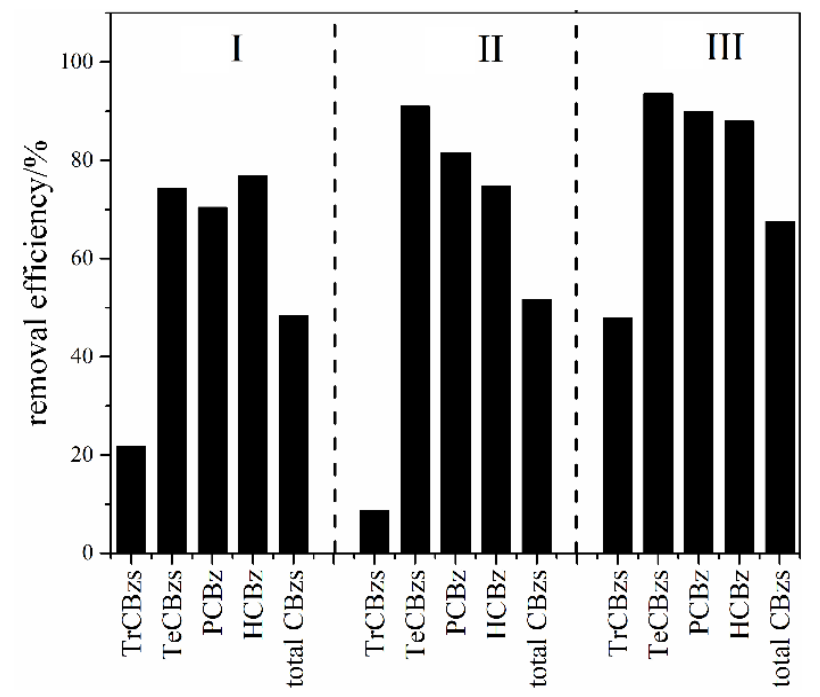

Fig. 10. The removal efficiencies of different CBzs from $\mathrm{SDFGD}+\mathrm{AC}+\mathrm{BF}$.

\section{Removal Efficiencies of PCDD/Fs and CBzs by the SCR Reactor}

The effects on the distributions and removal efficiencies of PCDD/Fs by the SCR reactor of MSWI I are shown in Figs. 11 and 12. OCDD dominated all PCDD/Fs in flue gas before the SCR reactor with a fraction of $66.2 \%$. The main PCDF congeners were 2,3,7,8-TCDF and 2,3,4,7,8-PeCDF with fractions of $6.8 \%$ and $5.1 \%$, respectively. The fractions of $1,2,3,4,6,7,8-\mathrm{HpCDF}$ and OCDF increased to $6.0 \%$ and $4.1 \%$, respectively, when flue gas passed through the SCR reactor. Thus, PCDFs in flue gas were affected more by the $\mathrm{SCR}$ reactor. The removal efficiencies of each $\mathrm{PCDD} / \mathrm{F}$ congener were clearly different, which could be attributed to their differing oxidation capacities and volatilization

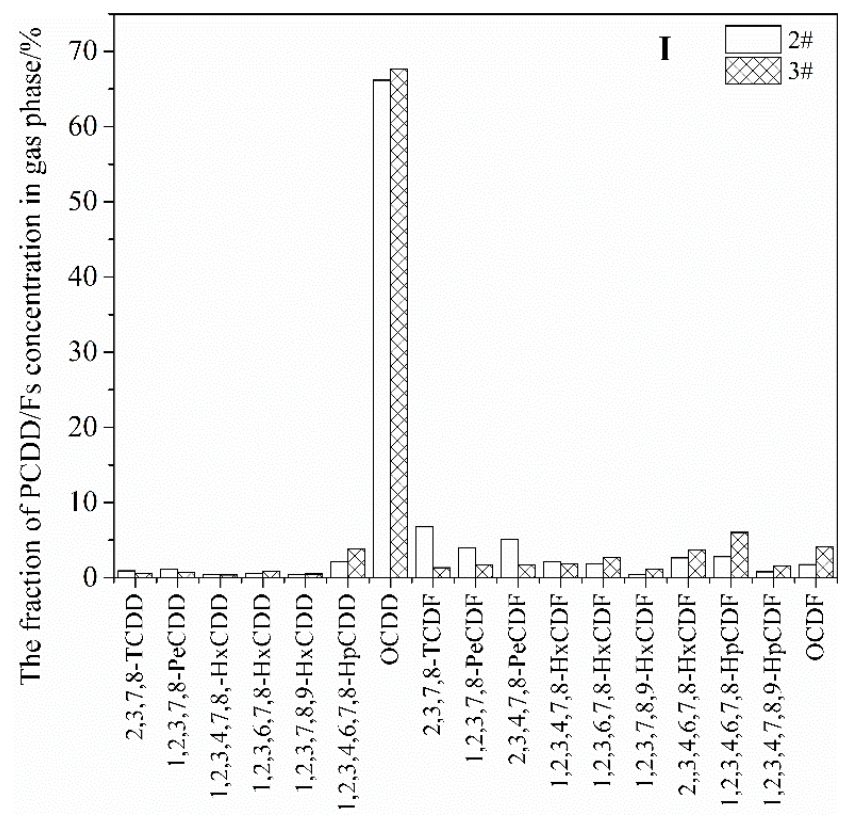

Fig. 11. The distributions of 17 gaseous $\mathrm{PCDD} / \mathrm{Fs}$ through the SCR reactor.

(Weber et al., 1999). Furthermore, the removal efficiencies of OCDD and OCDF were lower than those of other less chlorinated PCDDs and PCDFs. The removal efficiencies of 2,3,7,8-TCDD and 1,2,3,7,8-PeCDD were both higher than $80 \%$. Similarly, the removal efficiencies of $2,3,7,8$ TCDF, 1,2,3,7,8-PeCDF, and 2,3,4,7,8-PeCDF were all higher than $85 \%$. The removal efficiencies of 2,3,7,8-TCDF and 2,3,4,7,8-PeCDF could even reach as high as $93 \%$ and $90 \%$, respectively. This result was in accordance with those obtained from pilot tests in full-scale MSWIs (Li et al., 2018). This is because highly chlorinated PCDD/Fs have 


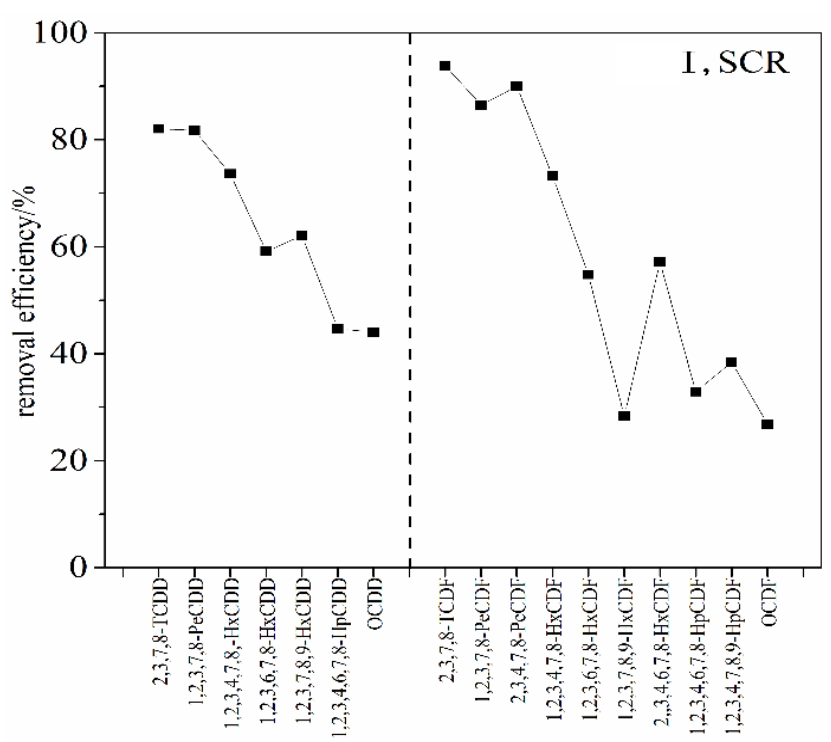

Fig. 12. The removal efficiencies of 17 gaseous PCDD/Fs through the SCR reactor.

higher vapor pressure and are easily adsorbed on the surface of catalysts to be decomposed. Therefore, catalysts need higher oxidation potential to handle the more highly chlorinated PCDD/Fs (Li et al., 2018).

The removal efficiencies of CBzs by the SCR reactor of MSWI I are shown in Fig. 13. The removal efficiencies of CBzs decreased as the chlorination level increased, which was similar to the results for PCDD/Fs. However, the removal efficiencies of all $\mathrm{CBzs}$ were considerably lower than those of PCDD/Fs. For instance, the efficiencies of trito hexa-chlorobenzenes were all below 25\%. CBzs and macromolecular chlorinated benzenes, such as PCDD/Fs, reformed simultaneously in actual flue gas. When flue gas passed through the SCR reactor, some PCDD/Fs could be reductively degraded to the CBzs on SCR catalyst, which could cause the increment of CBzs. Therefore, the removal efficiencies of CBzs were lower than that of PCDD/Fs.

\section{Memory Effects of the Wet Scrubber}

The wet scrubber is a typical deacidification device. Wevers et al. (1992) found that $71 \%$ of PCDD/Fs in flue gas could be removed through the wet scrubber. However, numerous studies have detected considerably higher levels of PCDD/Fs in the wet scrubber outlet which could therefore be a potential source of PCDD/Fs (Kreisz et al., 1996; Hunsinger et al., 1998; Gass et al., 2000; Kim et al., 2001; Löthgren and van Bavel, 2005). This source is named "the memory effect." In this research, different chlorinated PCDD/Fs in MSWI I and II increased through the wet scrubber. As shown in Fig. 14, the distributions of PCDDs and PCDFs did not change any great extent, which is in accordance with previous research from Takaoka (2002). More highly chlorinated PCDDs had higher concentration fractions. OCDD dominated among all the PCDDs. Moreover, the fractions of PCDF homologue increased and decreased as chlorination increased and HxCDF contributed most to the total PCDFs.

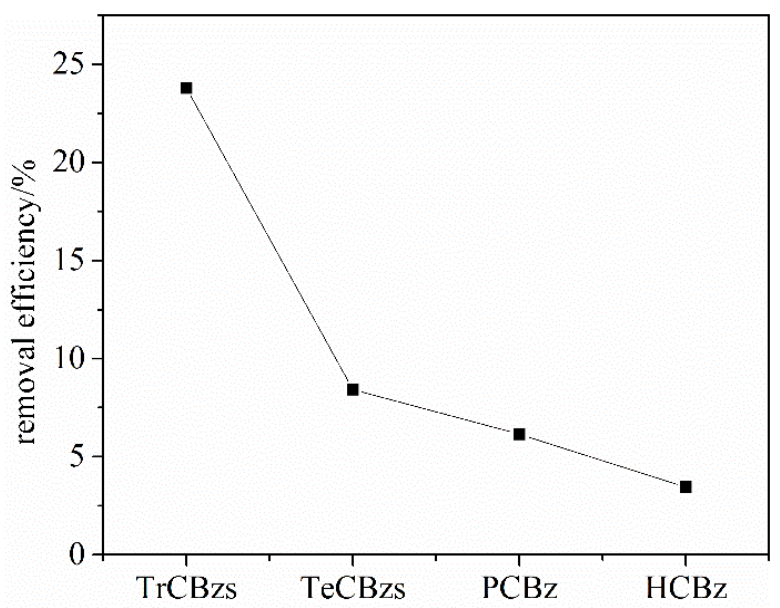

Fig. 13. The removal efficiencies of different CBzs through the SCR.

The increment of different chlorinated PCDD/Fs is shown in Fig. 15. All the PCDD/Fs clearly increased in MSWI I. The increment of both PCDDs and PCDFs increased and then decreased as chlorination increased. The concentration of HxCDD and PeCDD increased dramatically by 32 and 17 times, respectively, among all PCDDs from MSWI I. The same results were found for PCDFs, where penta- and hexachlorinated PCDFs increased by almost 20 times. The effects of the wet scrubber in MSWI II were considerably weaker than those in MSWI I. The highest increasing ratios of HpCDD and HpCDF were approximately 5.0.

Due to the strong memory effect of wet scrubber, the wet scrubber could be installed before the SCR reactor. The degraded on SCR catalyst to achieve higher removal PCDD/Fs derived from the memory effect could be efficiency. However, the adjustment would increase the consumption of energy on the steam gas heater due to the low outlet temperature of flue gas at the wet scrubber. Furthermore, the increasing vapor content in the flue gas after wet scrubber might affect the destruction behavior of PCDD/Fs by SCR catalyst. Therefore, the wet scrubber should be installed after the SCR reactor. The PCDD/F control efficiency can be improved by adjusting the operation temperatures of SCR system and wet scrubber more or less.

The effects on different chlorinated CBzs in flue gas were also investigated. As shown in Fig. 16, the increment ratio through the wet scrubber in MSWI I was almost around 1.0. However, the concentrations of all CBzs went up dramatically in MSWI II and III, especially TrCBzs which increased by 8.5 and 7.0 times, respectively.

\section{Correlations between PCDD/Fs and CBzs through the APCDs}

The concentrations of PCDD/Fs and total CBzs in the three MSWIs through all the APCDs are compared in Fig. 17. In MSWI I, the trends of PCDD/Fs and total CBzs were generally similar. In MSWI II and III, similar trend appeared through the SDFGD with AC injection and BF. The wet scrubbers seriously affected the relationships of PCDD/Fs and CBzs. In all MSWIs, the SDFGD with AC and BF worked 

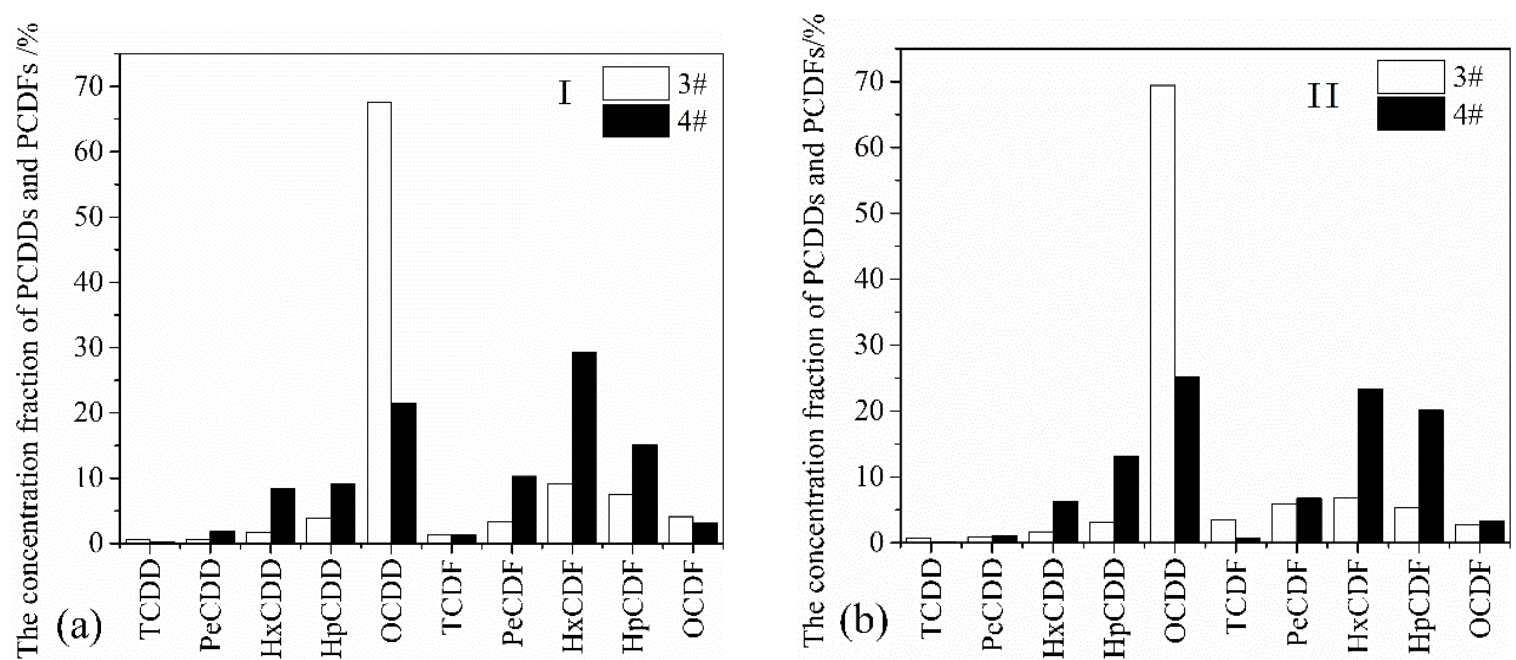

Fig. 14. The distributions of PCDDs and PCDFs through the wet scrubbers.

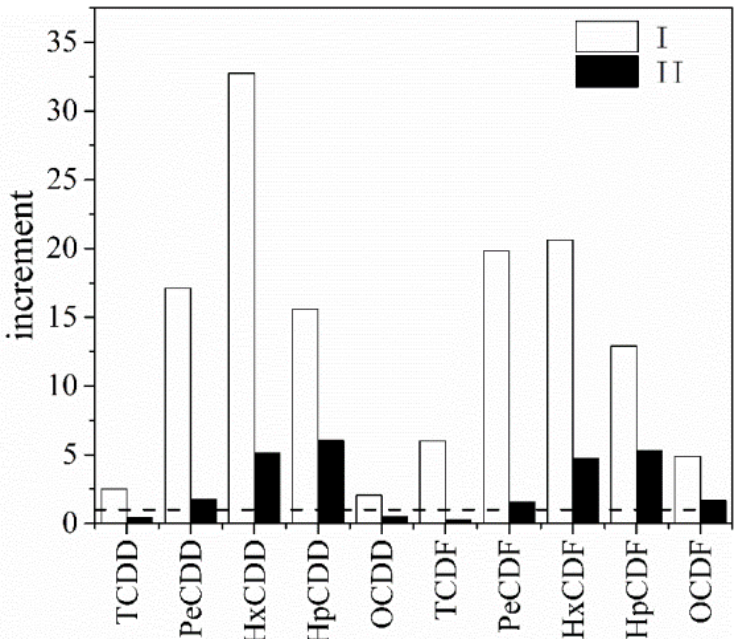

Fig. 15. The increment of different chlorinated PCDD/Fs through wet scrubbers.

effectively and revealed few effects on their correlations. Compared with other CBzs, TrCBzs were far more sensitive to the purification and exhibited significant changes through different purification devices, especially through the SCR reactor and wet scrubbers. The result showed that the correlations between PCDD/Fs and TrCBzs need to be considered separately, before and after the two devices were applied.

The correlations between TEQ and different CBzs through the APCDs were calculated in Table 3. Before the APCDs, all the TEQ values in MSWIs were above $1.0 \mathrm{ng} \mathrm{Nm}^{-3}$. TeCBzs and PCBzs had higher correlation coefficients. 1,2,3,4-TeCBz had the highest correlation with PCDD/Fs and could therefore be an indicator of PCDD/Fs. A linear correlation model (determination coefficient $\left[\mathrm{R}^{2}\right]=0.79$ ) and a quadratic correlation model $\left(\mathrm{R}^{2}=0.82\right)$ were then established, and are presented in Fig. 18.

After the APCDs, the emission levels of PCDD/Fs in MSWI II and III were in the range of $0.01-0.1 \mathrm{ng}$ I-TEQ $\mathrm{Nm}^{-3}$. The significant effects on CBzs by the SCR reactors and wet

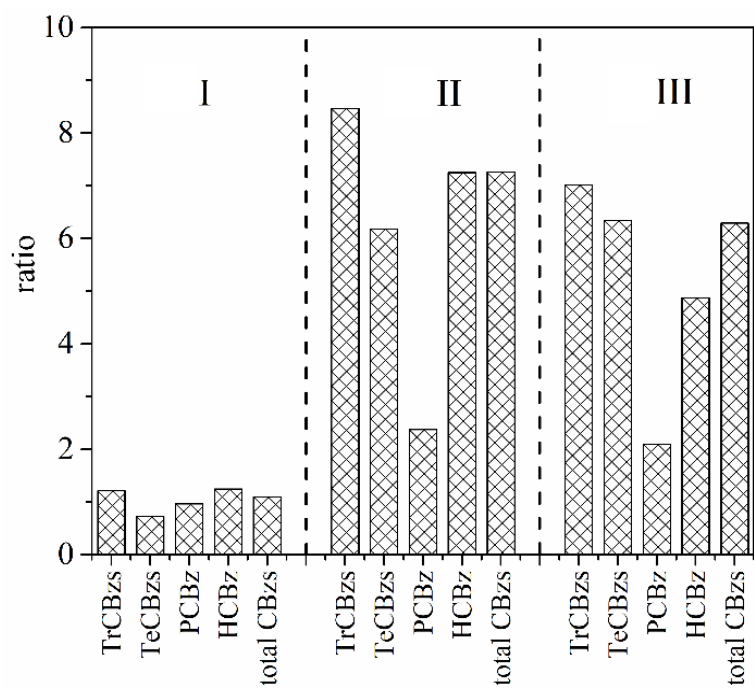

Fig. 16. The increment of different CBzs under the effects of wet scrubbers.

scrubbers resulted in poorer correlations between $\mathrm{PCDD} / \mathrm{Fs}$ and CBzs, and the different indicators. Following the purification system, the correlation coefficient between PCDD/Fs and CBzs had already fallen down to 0.51. 1,3,5$\mathrm{TrCBz}, 1,2,3-\mathrm{TrCBz}, 1,2,4,5-\mathrm{TeCBz}$ and $1,2,3,4-\mathrm{TeCBz}$ had correlation coefficients lower than 0.1 . However, 1,2,4TrCBz was found to establish a good correlation quadratic model with PCDD/Fs, as shown in Fig. 19. This raises the possibility that the effects of APCDs, especially the wet scrubber, on $\mathrm{PCDD} / \mathrm{Fs}$ and $1,2,4-\mathrm{TrCBz}$, were generally similar, although further detailed research is needed on wet scrubbers. This underlines the importance of establishing different correlation models before and after the APCDs to indirectly monitor the emission of PCDD/Fs.

\section{CONCLUSION}

This research investigated the removal of PCDD/Fs in three MSWIs by several typical flue gas purification 

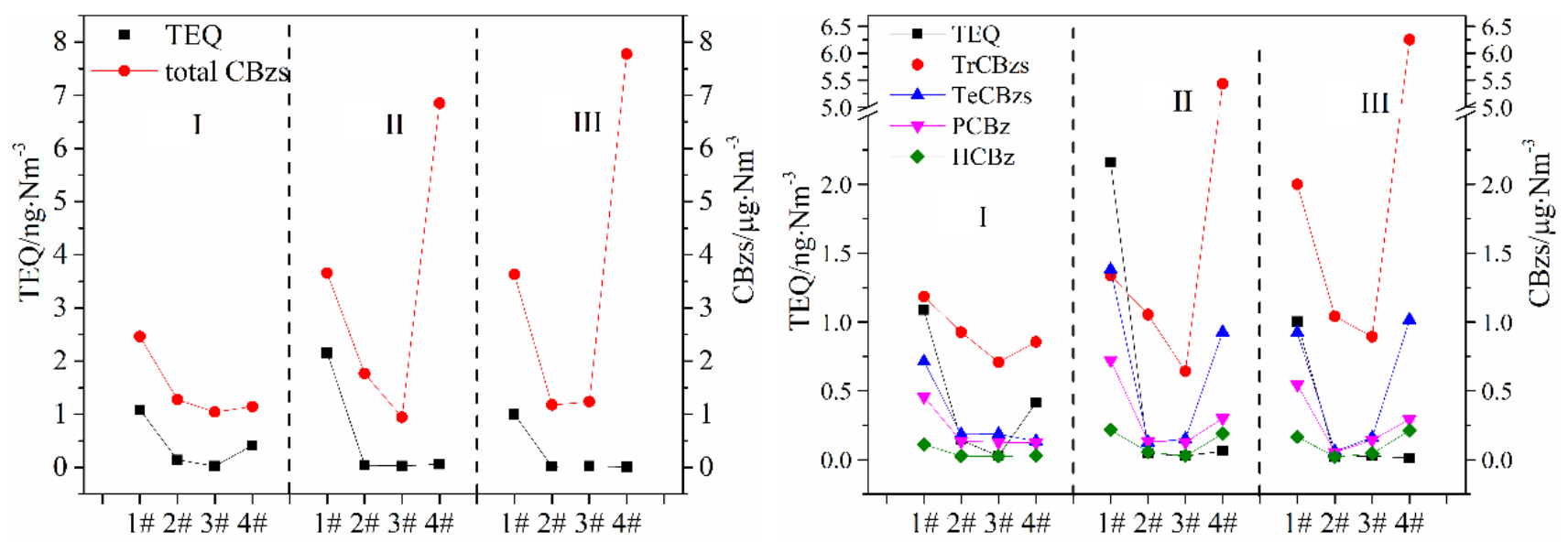

Fig. 17. The comparisons between TEQ and CBz through the APCDs.

Table 3. The correlation coefficients between TEQ and CBzs through the APCDs.

\begin{tabular}{lll}
\hline & (a) Before the APCDs & (b) After the APCDs \\
\hline $1,3,5-T r C B z s$ & 0.463 & 0.05 \\
$1,2,4-T r C B z s$ & 0.589 & $0.822^{*}$ \\
$1,2,3-T r C B z s$ & 0.568 & 0.013 \\
$1,2,3,5-T e C B z s$ & $0.810^{* *}$ & 0.165 \\
$1,2,4,5-T e C B z s$ & $0.678^{*}$ & 0.022 \\
$1,2,3,4-T e C B z s$ & $0.894^{*}$ & 0.016 \\
PCBzs & $0.865^{* *}$ & 0.277 \\
HCBzs & $0.770^{*}$ & 0.183 \\
TrCBzs & 0.307 & 0.534 \\
TeCBzs & $0.796^{*}$ & 0.054 \\
Total CBzs & 0.672 & 0.506 \\
\hline
\end{tabular}

** Significant at 0.01 level (two-tailed); * significant at 0.05 level (two-tailed).

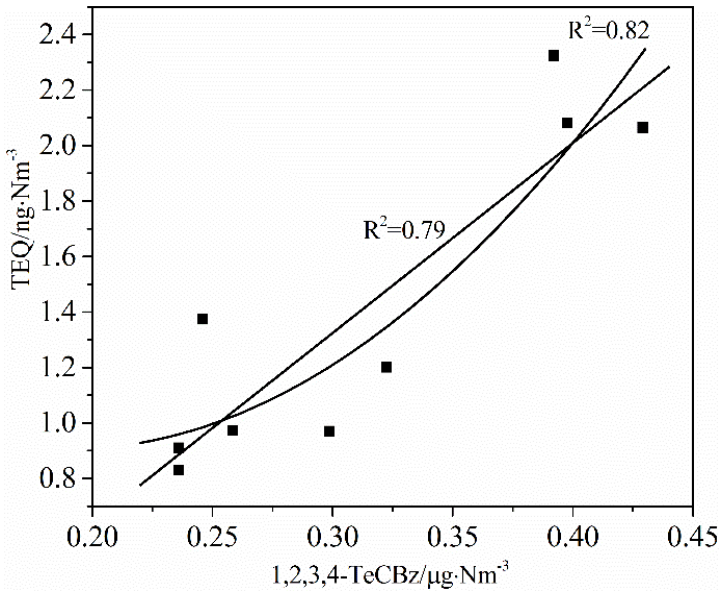

Fig. 18. The correlations between $1,2,3,4-\mathrm{TeCB}$ zs and TEQ before the APCDs.

devices: the SDFGD, which was equipped with an $\mathrm{AC}$ injector and BF; the SCR reactor; and the wet scrubber. The concentrations and homologue distributions of the PCDD/Fs and CBzs were examined as well as the correlations between these two groups of pollutants.

We found that the concentrations of PCDD/Fs were greatly reduced by the purification devices. However, no trend was

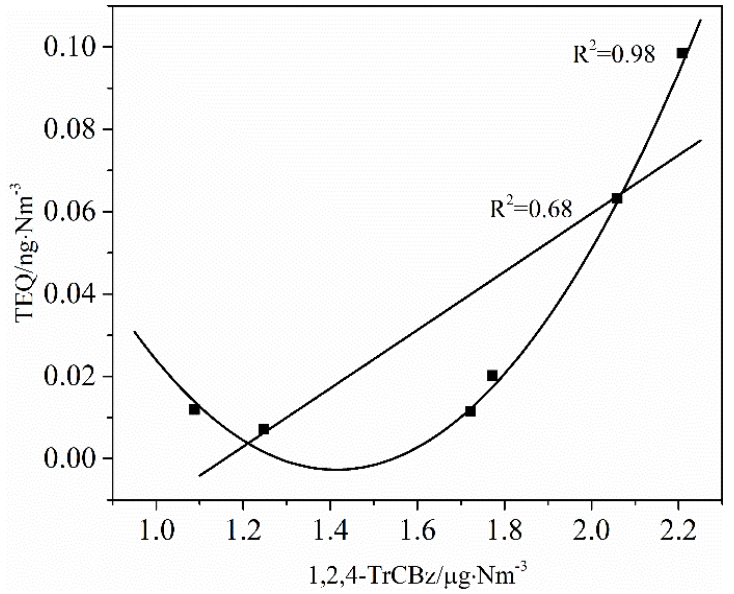

Fig. 19. The correlations between $1,2,4-\mathrm{TrCB} z$ and TEQ after the APCDs.

found for the CBzs, which either decreased by $53.7 \%$ or increased dramatically. The SDFGD system with an AC injector and $\mathrm{BF}$ displayed similar removal efficiencies for both PCDD/Fs and CBzs and the lowest removal efficiency for less chlorinated TrCBzs, which were difficult to adsorb.

The SCR reactor achieved different removal efficiencies for the various PCDD/Fs in the flue gas; the removal 
efficiency for CBzs was significantly lower, however. Additionally, the removal efficiencies for both PCDD/Fs and CBzs decreased as the chlorination increased, as less chlorinated compounds were easier to remove.

The "memory effect" in the wet scrubber increased the PCDD/F concentrations, especially for penta- to heptachlorinated PCDD/Fs, which rose substantially when the flue gas passed through this device. Due to the effects of APCDs, especially wet scrubbers, the correlations between $\mathrm{PCDD} / \mathrm{F}$ and $\mathrm{CBz}$ removal must be individually evaluated per device in order to develop the most accurate monitoring models. For instance, the PCDD/F concentration in the flue gas exhibited the strongest correlation with that of 1,2,3,4$\mathrm{TeCBz}$ prior to the APCDs, but $1,2,4-\mathrm{TrCBz}$ was a better indicator when assessing the removal efficiency for PCDD/Fs.

\section{ACKNOWLEDGEMENTS}

This research was supported by the National Key Research and Development Program of China (2018YFC1802100). National Natural Science Foundation of China (Grant No. 51621005). This manuscript was edited by Wallace Academic Editing.

\section{REFERENCES}

Altwicker, E., Konduri, R., Lin, C. and Milligan, M. (1992). Rapid formation of polychlorinated dioxins/furans in the post combustion region during heterogeneous combustion. Chemosphere 25: 1935-1944. https://doi.org/10.1016/00456535(92)90032-M

Ballschmiter, K., Braunmiller, I., Niemczyk, R. and Swerev, M. (1988). Reaction pathways for the formation of polychloro-dibenzodioxins (PCDD) and - dibenzofurans (PCDF) in combustion processes: II. Chlorobenzenes and chlorophenols as precursors in the formation of polychloro-dibenzodioxins and - dibenzofurans in flame chemistry. Chemosphere 17: 995-1005. https://doi.org/10. 1016/0045-6535(88)90070-7

Bhavsar, S.P., Reiner, E.J., Hayton, A., Fletcher, R. and MacPherson, K. (2008). Converting Toxic Equivalents (TEQ) of dioxins and dioxin-like compounds in fish from one Toxic Equivalency Factor (TEF) scheme to another. Environ. Int. 34: 915-921. https://doi.org/10.1016/j.envint. 2008.02.001

Chen, T., Wang, T., Yang, J., Ji, L., Zhou, G., Zhan, M., Li, X. and Lin, X. (2018). The behaviors and relationships of PCDD/Fs and chlorobenzenes in the whole process of one municipal solid waste incinerator. Aerosol Air Qual. Res. 18: 3134-3146. https://doi.org/10.4209/aaqr.2018.03.0092

Dong, C., Jin, B., Zhong, Z. and Lan, J. (2002). Tests on cofiring of municipal solid waste and coal in a circulating fluidized bed. Energ. Convers. Manage. 43: 2189-2199. https://doi.org/10.1016/S0196-8904(01)00157-1

EPA (1995). EPA Method 23. Determination of polychlorinated dibenzo-pdioxins and polychlorinated dibenzofurans from municipal waste combustors. U.S. Environmental Protection Agency, USA.

Gass, H.C., Sunderhauf, W., Rotard, W. and Jager, J. (2000).
Secondary analysis of dioxin emission data of a municipal solid waste incinerator. Organohalogen Compd. 46: 154157.

Gullett, B.K., Oudejans, L., Tabor, D., Touati, A. and Ryan, S. (2011). Near-real-time combustion monitoring for PCDD/PCDF indicators by GC-REMPI-TOFMS. Environ. Sci. Technol. 46: 923-928. https://doi.org/10.1021/es202 7339

Han, Y., Liu, W., Li, H., Lei, R., Gao, L., Su, G. and Liu, G. (2017). Gas-particle partitioning of polychlorinated dibenzo- $p$-dioxins, dibenzofurans, and biphenyls in flue gases from municipal solid waste incinerators. Aerosol Air Qual. Res. 17: 2847-2857. https://doi.org/10.4209/aaqr. 2017.09.0308

Hsieh, Y.K., Chen, W.S., Zhu, J. and Huang, Q. (2018). Characterization of polychlorinated dibenzo- $p$-dioxins and dibenzofurans of the flue gases, fly ash and bottom ash in a municipal solid waste incinerator. Aerosol Air Qual. Res. 18: 421-432. https://doi.org/10.4209/aaqr.2017. 12.0564

Hu, J., Zheng, M., Liu, W., Li, C., Nie, Z., Liu, G., Zhang, B., Xiao, K. and Gao, L. (2013). Characterization of polychlorinated naphthalenes in stack gas emissions from waste incinerators. Environ. Sci. Pollut. Res. 20: 29052911. https://doi.org/10.1007/s11356-012-1218-0

Hunsinger, H., Kreisz, S. and Seifert, H. (1998). PCDD/F behavior in wet scrubbing systems of waste incineration plants. Chemosphere 37: 2293-2297. https://doi.org/10.10 16/S0045-6535(98)00285-9

Kato, M. and Urano, K. (2001). A measuring method of chlorobenzenes as a convenient substitute index of dioxins in stack gas from waste incineration facilities. Waste Manage. 21: 63-68. https://doi.org/10.1016/S0956053X(00)00049-0

Kim, S.C., Jeon, S.H., Jung, I.R., Kim, K.H., Kwon, M.H., Kim, J.H., Yi, J.H., Kim, S.J., You, J.C. and Jung, D.H. (2001). Removal efficiencies of PCDDs/PCDFs by air pollution control devices in municipal solid waste incinerators. Chemosphere 43: 773-776. https://doi.org/ 10.1016/S0045-6535(00)00432-X

Kreisz, S., Hunsinger, H. and Vogg, H. (1996). Wet scrubbers - A potential PCDD/F source? Chemosphere 32: 73-78. https://doi.org/10.1016/0045-6535(95)00229-4

Kulkarni, P.S., Crespo, J.G. and Afonso, C.A. (2008). Dioxins sources and current remediation technologies-A review. Environ. Int. 34: 139-153. https://doi.org/10.1016/ j.envint.2007.07.009

Kuzuhara, S., Sato, H., Tsubouchi, N., Ohtsuka, Y. and Kasai, E. (2005). Effect of nitrogen-containing compounds on polychlorinated dibenzo- $p$-dioxin/dibenzofuran formation through de novo synthesis. Environ. Sci. Technol. 39: 795-799. https://doi.org/10.1021/es049040j

Lavric, E.D., Konnov, A.A. and De Ruyck, J. (2005). Surrogate compounds for dioxins in incineration. A review. Waste Manage. 25: 755-765. https://doi.org/10.1016/j.was man.2004.12.026

Li, S.U., Liu R.J. and Tu, J. (2017). Municipal waste incineration flue gas purification technology. Power Sys. Eng. 33: 83-84. (in Chinese) 
Li, Y., Yu, G., Huang, J., Wang, B., Deng, S. and Wang, Y. (2018). Catalytic decomposition of dioxins and other unintentional POPs in flue gas from a municipal waste incinerator (MWI) in China: A pilot testing. Environ. Sci. Pollut. Res. 25: 31799-31804. https://doi.org/10.1007/s1 1356-016-6554-Z

Löthgren, C.J. and van Bavel, B. (2005). Dioxin emissions after installation of a polishing wet scrubber in a hazardous waste incineration facility. Chemosphere 61: 405-412. https://doi.org/10.1016/j.chemosphere.2005.02.015

Oh, J.E., Gullett, B., Ryan, S. and Touati, A. (2007). Mechanistic relationships among PCDD/Fs, PCNs, PAHs, ClPhs, and ClBzs in municipal waste incineration. Environ. Sci. Technol. 41: 4705-4710. https://doi.org/10. 1021/es0629716

Ruegg, H. and Sigg, A. (1992). Dioxin removal in a wet scrubber and dry particulate remover. Chemosphere 25: 143-148. https://doi.org/10.1016/0045-6535(92)90499-H

Ruokojärvi, P., Asikainen, A., Ruuskanen, J., Tuppurainen, K., Mueller, C., Kilpinen, P., and Yli-Keturi, N. (2001). Urea as a $\mathrm{PCDD} / \mathrm{F}$ Inhibitor in Municipal Waste Incineration. J. Air Waste Manage. Assoc. 51: 422-431. https://doi.org/10.1080/10473289.2001.10464279

Ruokojärvi, P.H., Halonen, I.A., Tuppurainen, K.A., Tarhanen, J., and Ruuskanen, J. (1998). Effect of Gaseous Inhibitors on PCDD/F Formation. Environ. Sci. Technol. 32: 3099-3103. https://doi.org/10.1021/es9701265

Takaoka, M. (2002). The behavior of PCDD/Fs, PCBs, chlorobenzenes and chlorophenols in wet scrubbing system of municipal solid waste incinerator. Chemosphere 53: 153-161. https://doi.org/10.1016/S0045-6535(03)00437-5

Tian, B., Huang, J., Deng, S.B., Yang, S.W., and Yu, G. (2010). Catalytic decomposition of PCDD/Fs from flue Gas. Prog. Chem. 22: 1836-1843. (in Chinese)

Trivedi, J. and Majumdar, D. (2013). Memory effect driven emissions of persistent organic pollutants from industrial thermal processes, their implications and management: A review. J. Environ. Manage. 119: 111-120. https://doi.org/ 10.1016/j.jenvman.2013.01.026

Wang, T., Chen, T., Lin, B., Lin, X., Zhan, M. and Li, X. (2017a). Emission characteristics and relationships among PCDD/Fs, chlorobenzenes, chlorophenols and PAHs in the stack gas from two municipal solid waste incinerators in China. RSC Adv. 7: 44309-44318. https://doi.org/10.1039/C7RA04168C

Wang, T., Chen, T., Lin, X., Zhan, M. and Li, X. (2017b). Emission and distribution of PCDD/Fs, chlorobenzenes, chlorophenols, and PAHs from stack gas of a fluidized bed and a stoker waste incinerator in China. Environ. Sci. Pollut. Res. 24: 5607-5618. https://doi.org/10.1007/s113 56-016-8221-9

Weber, R., Sakurai, T. and Hagenmaier, H. (1999). Low temperature decomposition of PCDD/PCDF, chlorobenzenes and PAHs by $\mathrm{TiO}_{2}$-based $\mathrm{V}_{2} \mathrm{O}_{5}-\mathrm{WO}_{3}$ catalysts. Appl. Catal., B 20: 249-256. https://doi.org/10. 1016/S0926-3373(98)00115-5

Wevers, M., De Fre, R., Rymen, T. and Geuzens, P. (1992). Reduction of dioxin emission from a municipal waste incinerator by wet gas scrubbing. Chemosphere 25: 14351439. https://doi.org/10.1016/0045-6535(92)90166-O

Wielgosiński, G. (2010). The possibilities of reduction of polychlorinated dibenzo-p-dioxins and polychlorinated dibenzofurans emission. Intern. J. Chem. Eng. 2010: 392175. https://doi.org/10.1155/2010/392175

Yan, M. (2012). Inhibition of PCDD/Fs formation during medical waste incineration and research of environmental impact of incinerator. Doctoral thesis, Zhejiang University, China.

Yan, M., Li, X., Chen, T., Lu, S. and Yan, J. (2010). Investigation of PCDD/Fs indicators in flue gas from waste incinerators. J. Combust. Sci. Technol. 3: 014. (in Chinese)

Yin, X.F., Li, X.D., Lu, S.Y., Luo, J.S., Gu, Y.L., Yan, J.H., Ni, M.J. and Cen, K.F. In (Ed. $)^{\wedge}($ Eds.) Zhongguo Dianji Gongcheng Xuebao (Proceedings of the Chinese Society of Electrical Engineering), 2007, pp. 29-33.

Yu, M.F., Li, X.D., Li, W.W., Chen, T. and Yan, J.H. (2016b). Catalytic destruction of pcdd/fs over the new vanadium based oxide catalysts. J. Zhejiang Univ. (Eng. Sci.) 50: 2052-2057. (in Chinese). https://doi.org/10.3785 /j.issn.1008-973X.2016.11.002

Yu, M.F., Li, X.D., Ren, Y., Chen, T., Lu, S.Y. and Yan, J.H. (2016a). Low temperature oxidation of PCDD/Fs by $\mathrm{TiO}_{2}$-based $\mathrm{V}_{2} \mathrm{O}_{5} / \mathrm{WO}_{3}$ catalyst. Environ. Prog. Sustainable 35: 1265-1273. https://doi.org/10.1002/ep.12339

Zhou, S. (2017). Analysis and selection of purification process of flue gas pollutants from municipal solid waste incineration. Environ. Dev. 3: 33. (in Chinese) https://doi.org/10.16647/j.cnki.cn15-1369/X.2017.03.025

Received for review, December 1, 2019 Revised, February 23, 2020 Accepted, March 23, 2020 